\title{
Using Pre-Identified Attributes as the Critical Success Factors of College Leadership to Measure Candidates
}

\author{
Michael F. Frimpon ${ }^{1}$ \\ ${ }^{1}$ Ghana Institute of Management and Public Administration (GIMPA), Achimota, Ghana \\ Correspondence: Michael F. Frimpon, Ghana Institute of Management and Public Administration (GIMPA), \\ Achimota, Ghana. Tel: 233-20-250-4498. E-mail: mfrimpon@gimpa.edu.gh
}

Received: May 29, 2012 Accepted: June 26, 2012 Online Published: September 16, 2012

doi:10.5539/ijbm.v7n18p158 URL: http://dx.doi.org/10.5539/ijbm.v7n18p158

\begin{abstract}
The selection of a school leader is a multi attribute problem that needs to be addressed taking into consideration the peculiar needs of an institution. This paper is intended to specify the critical success factors (CSFs) of college leaders as perceived by students. A survey comprising the 37 attributes of The Leaders Attributes Inventory (LAI) of Moss was given to the students in a local university to determine their best 10 . The 10 selected attributes were mapped onto the Leadership Effectiveness Index (LEI) where they were grouped under the 3 categories of Social Skills, Management Skills and Personal Characteristics. The top three attributes identified were "Visionary, Planning and Achievement oriented". The research seeks to contribute to the understanding of the critical success factors of college leadership. Another objective of the study is to create a model to measure candidates using the attributes so identified.
\end{abstract}

Keywords: attributes, Leaders Attributes Inventory (LAI), feasible space, Critical Success Factors (CSFs)

\section{Introduction}

Few positions come with the reverence of the leadership of a high-profile college or university. There is unanimity that most of these leaders do perform to the satisfaction of their appointing bodies. But the pushback against some of their decisions, sporadic agitations by students for their replacement, and subliminal subversion by certain interest groups could be a pointer to the fact that all is not quiet at that front. Nevertheless practically all these consensus leaders survive their storms and serve until the end; which then triggers the search for another lifetime replacement because it is a rarity for college presidents to be removed or changed before the end of their tenure or mandated retirement age. The leader has different captions such as president, rector, vice-chancellor etc. This paper will use the American term of president to represent this function of leadership. Thus the president in this study is defined as the highest ranking person of leadership within the college or university. The concept of a college presidency is based on the administrative model of the English universities of Oxford and Cambridge (Cowley, 1980) over 800 years ago. Since then many different governance systems have evolved commensurate with the growth of higher education across the globe.

\section{What is Leadership?}

Neustadt defined presidential power simply as the power to persuade (Klitgaard, 1990), and a president who has to use fiat and threats of sanctions due to his inability to inspire his followers' to tow the line will be largely ineffective.

"Leadership involves persuading other people to set aside for a period of time their individual concerns and to pursue a common goal that is important for the responsibilities and welfare of a group. Leadership is persuasion, not domination; persons who can require others to do their bidding because of their power are not leaders. Leadership only occurs when others willingly adopt, for a period of time, the goals of a group as their own" (Hogan et.al., 1994). This paraphrase is a classic encapsulation of the difference between good leaders and mere leaders. There are stirring examples of folkloric leadership that transcend time and space. Apple computers with and without Steve Jobs is the quintessence in the criticality of leadership, and Jose Mourinho who has climbed the winners pedestal in Portugal, England, Italy and Spain is a testament to the fact that good leadership counts for something.

For examples of great leadership, we look no further than the military, and here is one: 
"More than that, he had a rare intuition, a nearly flawless inner sense for other men's strengths that allowed him to see the spark of leadership in others, and when he saw that spark, to place such men into key assignments and then to fully support their efforts. He did that time and again, hundreds of times, with remarkable accuracy".

These remarks were delivered by Gen. John M. Shalikashvili, chairman, Joint Chiefs of Staff, of the United States army at the George C. Marshall ROTC Award Seminar, Virginia Military Institute, Lexington, Virginia in April 12, 1995. Gen. Marshall is remembered best as the architect of the Marshall plan, the initiative that helped rebuild Europe and Japan after the Second World War.

According to the American Association of University Professors (AAUP), the statement below "remains the Association's central policy document relating to academic governance."

"As the chief planning officer of an institution, the president has a special obligation to innovate and initiate. The degree to which a president can envision new horizons for the institution, and can persuade others to see them and to work toward them, will often constitute the chief measure of the president's administration" (AAUP, 1966).

A leader cannot exist in a vacuum; he needs to be complemented by a team of lieutenants ready to do his bidding. It is a mark of good leadership for the leader to assemble a team of willing disciples to facilitate the prosecution of his agenda.

"A number of leaders fail for personal rather than structural or economic reasons. They may be skilled in a particular area, such as accounting, engineering, or sales. They fail because they can no longer rely solely on their own skills and effort; that is, they have been promoted into positions that require them to work through others to be successful" (Hogan et. al, 1994).

Great leaders are looked upon with awe because they can tackle and handle a whole swathe of initiatives that are deemed beyond the capabilities of one human. This they accomplish through their uncanny ability to work with and through people. To be effective a leader cannot be bogged down in marathon meetings and the monotony of daily operations. A leader needs to use mediums to be relieved from the tedium. As Hogan said above a leader's job is in the visioning and strategic articulation of the mission of the institution.

A leader must also exhibit independence and relevance. This is the quality of showing through actions that he is his own man, so to speak. A subservient leader is necessarily an expendable one. Even though institutional governance is a shared one, the leader must resist being the vehicle through which parallel or superimposed bodies rule while he reigns; for at the end of the day it is his legacy that is at stake.

"Colleges have evolved into more than just educational institutions of higher learning and today's college president will serve a different role than their predecessor. Colleges are a complex system composed of a series of subsystems: a lay governing board, a professional faculty sub divided into departments according to specialties, students, administrators, librarians, athletic coaches, and service personnel" (Dodds, 1962).

Large Universities are a microcosm of a nation, and the attributes to lead this complex organism mirror that of the nation at large. Getting a handle on these attributes and knowing how to use them to evaluate applicants is an imperative first step in selecting a "best" leader.

\subsection{Success Factors of College Leadership}

An exercise like the selection of a college leader is an undertaking of enormous proportions involving a multiplicity of factors that impact the process to varying degrees. A factor that is critical to the success of this kind of exercise is intuitively referred to as a Critical Success factor (CSF). Therefore, critical success factors (CSFs) are variables that are fundamental to the success of the selection of the leader, and an institution must handle these CSFs well in order to have a successful exercise (Frimpon, 2012).

The job demands that a candidate possess many special qualities known here as attributes. "Attributes act as predispositions, facilitators, and constraints which predispose and shape behaviors in a wide array of tasks, groups, and contexts; the greater the latitude provided by the situation, the more likely it is that attributes will shape behavior" (Moss et. al, 1991).

These attributes serve as the inputs to the person-system which can be transformed into outputs of behaviors suitable for the position of college leader. Of course the mapping of attributes to behaviors is not necessarily one-one or linear, but the correlation is obvious. Thus the possession of a certain set of particular attributes by a person can cause us to predict the behavior and character framework of the leader. The converse is also true. It is important to find out about the attributes of candidates. They are the peep holes through which we can take a peek at their inner selves and predict their future behaviors. 


\subsubsection{Leadership Attributes}

The attributes for leadership are varied and many. The Leadership Attributes Inventory (LAI) by (Moss et. al, 1991) is about the most comprehensive list put together to evaluate leadership in academia. Table 1 is the full complement of the attributes in the LAI.

Table 1. The Leadership Attributes Inventory (LAI) created by Moss and Laing (1990)

\begin{tabular}{|c|c|c|}
\hline \# & Attribute & Description \\
\hline 1 & Energetic with stamina & $\begin{array}{l}\text { Approaches tasks with great energy and works long hours when } \\
\text { necessary. }\end{array}$ \\
\hline 2 & Insightful & $\begin{array}{l}\text { Reflects on the relationship among events and grasps the meaning of } \\
\text { complex issues quickly. }\end{array}$ \\
\hline 3 & Adaptable, open to change & $\begin{array}{l}\text { Encourages and accepts suggestions and constructive criticism from } \\
\text { co-workers, and is willing to consider modifying plans. }\end{array}$ \\
\hline 4 & Visionary & $\begin{array}{l}\text { Looks to the future and creates new ways in which the organization can } \\
\text { prosper. }\end{array}$ \\
\hline 5 & $\begin{array}{l}\text { Tolerant of ambiguity and } \\
\text { complexity }\end{array}$ & $\begin{array}{l}\text { Comfortably handles vague and difficult situations where there is no } \\
\text { simple answer or no prescribed method of proceeding. }\end{array}$ \\
\hline 6 & Achievement oriented & $\begin{array}{l}\text { Shows commitment to achieving goals and strives to keep improving } \\
\text { performance. }\end{array}$ \\
\hline 7 & Accountable & Holds self-answerable for work and willingly admits mistakes. \\
\hline 8 & Initiating & Frequently introduces new ideas. \\
\hline 9 & Confident, accepting of self & Appears secure about abilities and recognizes personal shortcomings. \\
\hline 10 & $\begin{array}{l}\text { Willingness to accept } \\
\text { responsibility }\end{array}$ & $\begin{array}{l}\text { Willingly assumes higher level duties and functions within the } \\
\text { organization. }\end{array}$ \\
\hline 11 & Persistent & Continues to act on beliefs despite unexpected difficulties. \\
\hline 12 & Enthusiastic, optimistic & $\begin{array}{l}\text { Thinks positively, approaches new tasks with excitement, and deals with } \\
\text { challenges as opportunities. }\end{array}$ \\
\hline 13 & Tolerant of frustration & Acts calmly and patiently even when things don't go as planned. \\
\hline 14 & Dependable, reliable & Can be counted on to follow through to get the job done. \\
\hline 15 & Courageous, risk-taker & Willingly tries out new ideas in spite of possible loss or failure. \\
\hline 16 & Even disposition & $\begin{array}{l}\text { Displays a sense of humor and a stable temperament even in stressful } \\
\text { situations. }\end{array}$ \\
\hline
\end{tabular}

17 Committed to the common Works to benefit the entire organization, not just self. good

18 Personal integrity Speaks frankly and honestly and practices espoused values.

19 Intelligent with practical Learns quickly, and knows how and when to apply knowledge. judgment

20 Ethical

Acts consistently with principles of fairness and right or good conduct that can stand the test of close public scrutiny.

21 Communications (listening, Listens closely to people at work, and organizes and clearly presents oral, written) information both orally and in writing.

22 Sensitivity, respect Shows genuine concern for the feelings of others and regard for them as individuals.

23 Motivating others

Creates an environment in which people want to do their best.

24 Networking

Develops cooperative relationships within and outside of the organization. 


\section{Planning}

26 Delegating

27 Organizing

28 Team Building

29 Coaching

30 Conflict management

31 Time management

32 Stress management

33 Appropriate use leadership styles

34 Ideological beliefs are appropriate to the group

35 Decision making

36 Problem solving

37 Information management
In collaboration with others, develops tactics and strategies for achieving organizational objectives.

Appropriately and effectively assigns responsibility and authority.

Establishes effective and efficient procedures for getting work done in an orderly manner.

Facilitates the development of cohesiveness and cooperation among the people at work.

Helps people develop knowledge and skills for their work assignments.

Brings conflicts into the open and uses it to arrive at constructive solutions.

Schedules own work activities so that deadlines are met and work goals are accomplished in a timely manner.

Effectively deals with tension of high-pressure work solutions.

of Uses a variety of approaches to influence and lead others.

Models and demonstrated belief in the basic values of the organization.

Makes timely decisions that are in the best interest of the organizations by analyzing all available information, distilling key points, and drawing relevant organizations.

Effectively identifies, analyzes, and resolves difficulties and uncertainties at work.

Identifies, collects, organizes, and analyzes the essential information needed by the organization.

Even a cursory examination of these attributes can point to the fact that they holistically contribute to leadership effectiveness. They are thus Success Factors of leadership. The LAI will be a perfect starting point in measuring potential candidates and quantifying leadership of universities. The large number of attributes is an indicator of how difficult and complex this exercise is. But as large as the list of 37 attributes are, it is conceivable that research may throw in more.

\subsubsection{The Feasible Space of Leadership}

A good way of selecting the best possible leader is not to create the tradition of "leadership by promotion", where in effect the next leader is the deputy leader or someone close to the top. If the pool to select from is artificially narrowed to an identifiable few in high-echelon management, then the process reduces to "succession in a royal kingdom or caliphate". When searching for leaders it is better to throw the line in a larger pool where the chance of landing a big fish is high, than to fish in a pond in which floats the obvious one.

The following excerpt from the American Council of Trustees and Alumni (ACTA) explains a great deal about the difference in the process of choosing a mere leader and a great leader.

"In searching for an excellent candidate, do not tie your hands. A Ph.D. and 20 years in academic administration may be desirable, but experience has shown that they are not essential. Individuals who have shown leadership in other areas - business, government, the military, or the professions - have often made outstanding university presidents. What they lack in academic background they often make up for by their ability to 'think outside the box.' The description should never close the doors to strong but unconventional candidates and should make clear that selection procedures ensure equal opportunity and compliance with the law" (ACTA, 2003).

As in mathematical programming, a constraint causes shrinkage in the feasible space. In a leadership search exercise, a constraint like the above ACTA example removes a candidate from consideration regardless of other superior attributes such that individuals who have shown executive leadership like the ex-presidents of Ghana, Nigeria and other parts of Africa won't pass the litmus test of leadership. But one can only drool about the possibilities of the quantum jump in growth that would be brought to bear on an institution if an ex-president in any of these nations ever consented to taking up the mantle of leadership in a college. 
Another very obvious constraint is the low retirement age. The process of selecting a leader is arduous because a leader is not merely another employee. Therefore, it is a waste of precious search time for a leader to proceed on retirement after say 4 years of service. Table 2 - "Demographic Data Reponses of South Carolina Technical College presidents" shows that a full $50 \%$ of the college leaders are over 60 , the mandatory retirement age for school leaders in many African countries.

Table 2. Demographic data reponses of South Carolina technical college presidents

\begin{tabular}{lcc}
\hline Age & Frequency & Percentage \\
\hline $20-29$ & 0 & $0 \%$ \\
$30-39$ & 0 & $0 \%$ \\
$40-49$ & 0 & $0 \%$ \\
$50-59$ & 5 & $50 \%$ \\
$60-69$ & 5 & $50 \%$ \\
$70+$ & 0 & $0 \%$ \\
\hline
\end{tabular}

The United States knows the value of experience in college leadership as exemplified by the statement below: "By unanimous agreement trustees consider the selection of a new president their most important and critical responsibility. On the basis of national averages it is a duty they are called upon to perform once in eight to ten years. However, in many institutions the normal term of office is more like fifteen to twenty years, and individual trustees may perform this vital function only once in a lifetime (Dodds, H., 2001)". In the past 103 years, James Madison University has been led by only five presidents. The appointment of a college leader is the most important job by far for the trustees of an institution. It can also be disruptive and contentious; that is why it must be undertaken as infrequently as possible. In effect we should allow the leader to lead without the "sword of Damocles of forced retirement" hanging over his head even when he is alert, healthy and very capable.

\subsection{Research Methodology}

The purpose of this study is to identify the attributes needed by college leaders to be effective and successful.

The study has 3 components. 1) Identify the leadership attributes of a college president as obtains from the literature.

2) Identify the 10 best desired leadership attributes of a college president from the perspective of college students

3) Model the 10 attributes identified in (2) in a decision-analytic form. Such a decision model can aid search teams and stakeholders in selecting alternatives aka leaders in a process devoid of controversy.

A proven instrument titled the Leader Attribute Inventory (LAI) developed by Moss et al. was used as a template to identify the perceived leadership attributes of prospective college president's from students' perspective. The student body is normally not part of the search process in the selection of a school leader, and it is an object of intellectual curiosity to find out the attributes they expect their leaders to possess. The need to identify the qualities and abilities required to assume leadership is critical (Lazarick, 1999) because the functions of leadership are critical, and the process of choosing leaders should be subjected to analytic scrutiny. This particular set of attributes constitutes the critical success factors (CSFs) of college leadership.

"Leadership is like beauty, it's hard to define, but you know it when you see it" (Bennis, 1989). But as hard leadership is to define it is even harder to quantify. Nevertheless, since there are beauty contests, it is fair to say that beauty is measurable, and that is what this paper intends to do, measure leadership.

The search must entail a structured gathering and thorough examination of pertinent attributes, most of which can be garnered from the literature on how some schools did theirs. Table 3 is a catalog of attributes from disparate institutions and bodies that were informally used to measure candidates. (The numbers in parentheses are the locations of the attributes in the LAI (or their approximations in UVA)). 
Table 3. Desired leadership attributes of schools in the selection of their leaders

\begin{tabular}{llll}
\hline WOODBURY & UVA STUDENTS & AACC & GIMPA STUDENTS \\
\hline Academic Credentials & Passion (12) & Organizational Strategy & Visionary(4) \\
Inspirational Leadership & Innovative thinker (8) & Resource Management & Planning(25) \\
Entrepreneurial Spirit & Charisma (33) & Communication & Achievement oriented(6) \\
Organization & Promote diversity (22) & Collaboration & Decision making(35) \\
Planning, and Management & Effective fundraiser (24) & Community College & Problem solving(36) \\
Building Networks & & Advocacy & Committed to the common \\
Financial Responsibility & & Professionalism & good(17) \\
Fund Raising & Competency & Enthical(20) \\
Making Decisions & & & Motivating others(23) \\
Communication & & & Personal integrity(18) \\
Pursuit of Excellence & & & \\
\hline
\end{tabular}

The list from Woodbury comprises the Professional Background and Capabilities attributes, that together with the Personal and character attributes were used in their search. The AACC list embodies attributes that were obtained as a result of research. The UVA column is distilled from a Report the Student Consultation Group of UVA put forward by the student leadership to the search committee.

\subsubsection{Research Design}

The LAI was used to represent the required attributes for rating the hypothetical candidature for a college presidency. The participants of the study are undergraduate students in the business school of a local university. The student population of this university is about 5000 and comprises 5 schools made up of the following: Business, Law, Technology, Consultancy, and Governance.

Part I of the survey instrument requested demographic data while Part II comprised questions based on the Leader Attribute Inventory (LAI). The answers to the questions were on the format of a 6-point Likert scale. At this stage there wasn't much analysis to be done with the demography part due to the homogeneity of the groups.

\subsubsection{Survey Distribution and Data Collection}

A special mailing group was created from which an attachment of the survey instrument Table 4 was dispatched to four classes conveniently selected to take part in the study. The total intake of the classes was 171.

Table 4. Survey instrument for eliciting GIMPA student input

Part A. Demographic information

\begin{tabular}{lll}
\hline$Q 1 \quad$ & What is your region of origin? & Region of Origin \\
\hline Ashanti & Bono \\
Central & Eastern \\
Gt. Accra & Northern \\
Upper East \\
Upper West \\
Volta \\
Western \\
Other (Write country)
\end{tabular}




\begin{tabular}{lll}
\hline Q2 & What is your job situation and position? & Job Position \\
& Unemployed & \\
Junior Management & \\
Management & \\
Senior Management & \\
Retired & Gender \\
Other & \\
Are you female or male? & Program \\
Female & \\
Male & \\
What is your program of study in GIMPA? & \\
BEC & \\
BF & \\
BAC & \\
BMKT & \\
BHM & \\
MBA & \\
MS & \\
What is your level? & \\
100 & \\
200 & \\
300 & \\
400 & \\
Graduate &
\end{tabular}

Part B. Questionnaire on leadership

\begin{tabular}{ll}
\hline Rating System & 5 \\
\hline The attribute is important in all instances & 4 \\
The attribute is important in most instances & 3 \\
The attribute is somewhat important & 2 \\
The attribute is somewhat unimportant & 1 \\
The attribute is unimportant in most instances & 0 \\
The attribute is unimportant in all instances & \\
\hline
\end{tabular}

\begin{tabular}{|c|c|c|c|}
\hline$\#$ & Attribute & Description & $\begin{array}{llll}0 & 1 & 2 & 3\end{array}$ \\
\hline 1 & Energetic with stamina & $\begin{array}{l}\text { Approaches tasks with great energy and works long hours } \\
\text { when necessary. }\end{array}$ & \\
\hline 2 & Insightful & $\begin{array}{l}\text { Reflects on the relationship among events and grasps the } \\
\text { meaning of complex issues quickly. }\end{array}$ & \\
\hline 3 & $\begin{array}{l}\text { Adaptable, open to } \\
\text { change }\end{array}$ & $\begin{array}{l}\text { Encourages and accepts suggestions and constructive } \\
\text { criticism from co-workers, and is willing to consider } \\
\text { modifying plans. }\end{array}$ & \\
\hline 4 & Visionary & $\begin{array}{l}\text { Looks to the future and creates new ways in which the } \\
\text { organization can prosper. }\end{array}$ & \\
\hline
\end{tabular}


5 Tolerant of ambiguity and complexity

6

Achievement oriented

$7 \quad$ Accountable

$8 \quad$ Initiating

9

10

11 Persistent

Confident, accepting of self

Willingness to accept responsibility

\section{Enthusiastic,} optimistic

Tolerant of frustration

Dependable, reliable

Courageous, risk-taker

\section{Even disposition}

Committed to the common good

Personal integrity

Intelligent with practical judgment

Ethical

Communications (listening, oral, written)

\section{Sensitivity, respect}

Motivating others

Networking

Planning

Delegating

Organizing
Comfortably handles vague and difficult situations where there is no simple answer or no prescribed method of proceeding.

Shows commitment to achieving goals and strives to keep improving performance.

Holds self-answerable for work and willingly admits mistakes.

Frequently introduces new ideas.

Appears secure about abilities and recognizes personal shortcomings.

Willingly assumes higher level duties and functions within the organization.

Continues to act on beliefs despite unexpected difficulties.

Thinks positively, approaches new tasks with excitement, and deals with challenges as opportunities.

Acts calmly and patiently even when things don't go as planned.

Can be counted on to follow through to get the job done.

Willingly tries out new ideas in spite of possible loss or failure.

Displays a sense of humor and a stable temperament even in stressful situations.

Works to benefit the entire organization, not just self.

Speaks frankly and honestly and practices espoused values.

Learns quickly, and knows how and when to apply knowledge.

Acts consistently with principles of fairness and right or good conduct that can stand the test of close public scrutiny.

Listens closely to people at work, and organizes and clearly presents information both orally and in writing.

Shows genuine concern for the feelings of others and regard for them as individuals.

Creates an environment in which people want to do their best.

Develops cooperative relationships within and outside of the organization.

In collaboration with others, develops tactics and strategies for achieving organizational objectives.

Appropriately and effectively assigns responsibility and authority.

Establishes effective and efficient procedures for getting work done in an orderly manner. 


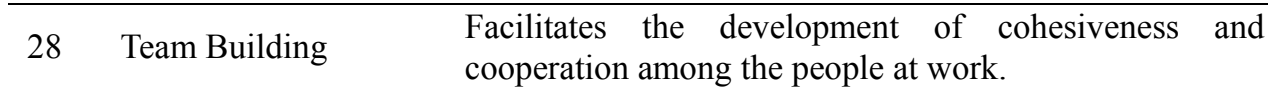

\section{Coaching}

30 Conflict management

31 Time management

32 Stress management

33 Appropriate use of leadership styles

Ideological beliefs are

34 appropriate to the group

35 Decision making

36 Problem solving

Information

management
Helps people develop knowledge and skills for their work assignments.

Brings conflicts into the open and uses it to arrive at constructive solutions.

Schedules own work activities so that deadlines are met and work goals are accomplished in a timely manner.

Effectively deals with tension of high-pressure work solutions.

Uses a variety of approaches to influence and lead others.

Models and demonstrated belief in the basic values of the organization.

Makes timely decisions that are in the best interest of the organizations by analyzing all available information, distilling key points, and drawing relevant organizations.

Effectively identifies, analyzes, and resolves difficulties and uncertainties at work.

Identifies, collects, organizes, and analyzes the essential information needed by the organization.

Do you feel there were any desirable leadership attributes that were not listed in the survey which should have been included? If so, please identify the attributes in \#s 38,39,40, and rate them like above:

38

39

40

41

Do you feel there were any attributes listed which should not have been included in the survey? If so, please identify the attribute(s) by writing their numbers and names below

Number

Attribute

Please write any comments and opinions here:

Note: The list below is the Leadership Attributes Inventory (LAI) created by Moss and Laing (1990)

The respondents were to download the file, save it, fill it on screen and return it. They were advised to discuss the document vigorously but complete it individually. About 70 questionnaires were returned to the same mailing group also by email attachment ensuring a totally paperless process. The response rate of about $40 \%$ is commendable because the respondents were not governance students and were thus not that politically involved. Less than half of the questionnaires were returned which is indicative of the fact that the exercise was not mandatory.

\subsubsection{Data Analysis}

Each returned questionnaire was examined. Usability was not much of an issue because a good amount of time was spent to educate the students on the use of the survey instrument, especially on the use of a Likert scale. A few attributes were not scored, which shouldn't be of much surprise because there are 37 of them. The mean and standard error and other statistics were determined by means of an Excel spreadsheet as in Table 5 below. The 
attributes were ranked based on the mean statistic, but if there is a tie then the attribute with the smaller standard error was ranked higher. Table 5 shows the ten top-ranked attributes. The number in parenthesis is the location of attribute in the LAI.

Table 5. GIMPA student rankings of 10 best attributes of the LAI (with locations of attributes in LAI in parentheses

\begin{tabular}{llccc}
\hline Mean Rank & Attribute (LAI \#) & Mean & STD Error (SE) & SE Rank \\
\hline 1 & Visionary(4) & 4.71 & 0.069 & 1 \\
2 & Planning(25) & 4.69 & 0.072 & 3 \\
3 & Achievement oriented(6) & 4.64 & 0.071 & 2 \\
4 & Decision making(35) & 4.64 & 0.089 & 14 \\
5 & Problem solving(36) & 4.59 & 0.080 & 6 \\
6 & Committed to the common good(17) & 4.56 & 0.072 & 4 \\
7 & Ethical(20) & 4.54 & 0.075 & 5 \\
8 & Enthusiastic, optimistic(12) & 4.53 & 0.086 & 11 \\
8 & Motivating others(23) & 4.53 & 0.086 & 11 \\
10 & Personal integrity(18) & 4.51 & 0.082 & 9 \\
\hline
\end{tabular}

\subsection{Discussion}

As can be seen from the spreadsheet; Visionary (Looks to the future and creates new ways in which the organization can prosper) came up as the attribute best required. What makes it truly the consensus top is the tightness in the values around it typified by the low value of the standard error.

Planning (In collaboration with others, develops tactics and strategies for achieving organizational objectives) which came in second had good tightness around it.

Decision making (Makes timely decisions that are in the best interest of the organizations by analyzing all available information, distilling key points, and drawing relevant conclusions), came in number three with good tightness around it. Achievement oriented (Shows commitment to achieving goals and strives to keep improving performance.) had the same mean value as the DM but it had a higher standard error and thus was relegated to the fourth position.

\subsection{Structuring the Attributes of Leadership}

The exercise to use this many attributes to evaluate candidates and select one out of a myriad of candidates, most with impeccable credentials is necessarily a complex one. But the process lends itself to defined optimization principles to make it painless and more transparent. Obviously a reduction in the number of attributes from 37 to 10 reduces the modeling complexity. But it is best to design a scalable model so that it will still be useful even outside the 10-attribute cap, after all the truncation to 10 attributes is artificial. We could very easily use 11,12 or even all 37 attributes.

It is helpful to put the attributes into categories where they together help achieve a sub-objective of the main objective of a successful exercise. This is particularly helpful if the emerging structure contains a relatively large number of attributes. "Grouping criteria can help the process of checking whether the set of criteria selected is appropriate to the problem, can ease the process of calculating criteria weights in some methods, and can facilitate the emergence of higher level views of the issues (UK DTLR, 2001). In order to reduce the complexity, the attributes will be grouped using the 3 clusters of the LEI as in Figure 1 below. 


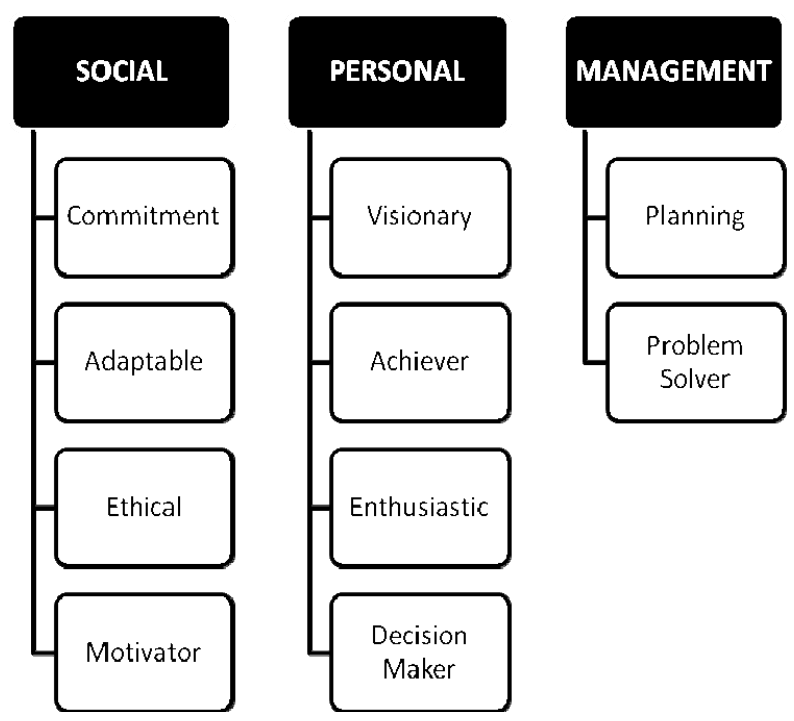

Figure 1. Attributes of the LAI grouped under the categories of the LEI

\subsection{Leader Effectiveness Index (LEI)}

Leader Effectiveness Index (LEI) is a survey instrument included as part of the Leader Attribute Inventory (LAI) form where the observer is asked to rank the overall leadership effectiveness of the one being rated. It proposes a clustering of the attributes into the three groups of i) Social skills and characteristics, ii) Personal characteristics, and iii) Management skills (Moss et.al, 1990). A simple placement of attributes into groups reduces complexity due to the basic Set theory formula below:

$$
\left(\operatorname{CSF}_{i} \bigcap \operatorname{CSF}_{j}\right)=\varnothing ; i \in \text { role } I \text {, and } j \in \text { role } J, I \neq J
$$

In the formula above, there is no interaction between attributes in different groups. Figure 1 depicts the hierarchical configuration of the model.

The LEI provides readymade groups into which the LAI attributes can be aggregated. These groups are the pillars upon which rest the success in choosing between good leaders and great leaders. The mere fact that the attributes can be ranked implies that they are not of the same significance and importance. Therefore the first step in using the model is to determine the weights for the (I) attributes and (II) groups.

Figure 2 below is a decision-analytic hierarchy of the 10 identified attributes with default equal weights.

This is only good as initial values for a beginning iteration. 


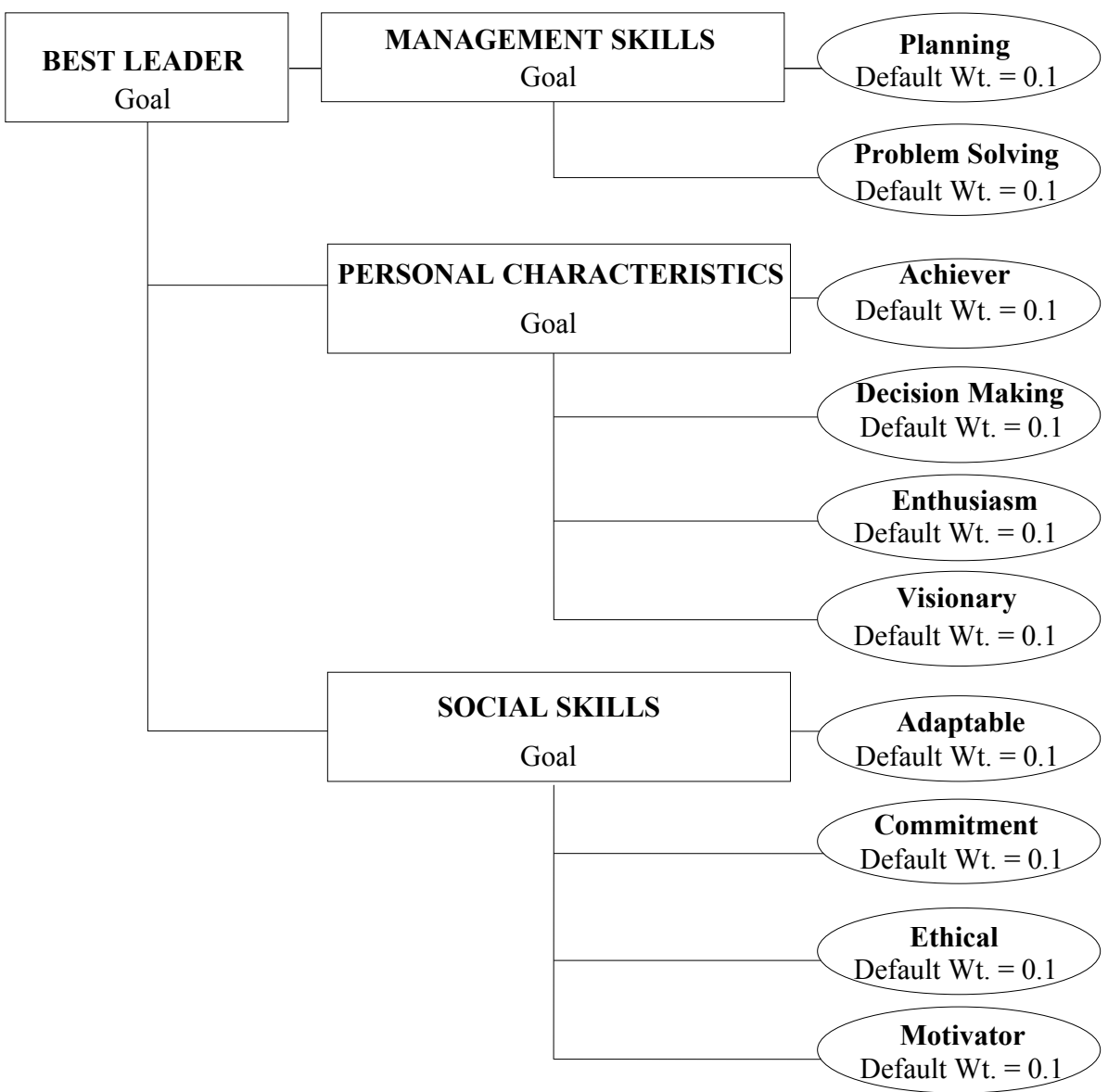

Figure 2. Decision-analytic hierarchy of the 10 identified attributes

\section{Conclusion}

This study set out to find out the desired attributes of a college leadership from the perspective of the college student body of a local university. The literature is replete with such information, but the Leadership Attributes Inventory (LAI) by Moss and Liang offered the best set for measuring leadership. The LAI can well be said to be the success factors of leadership. This subset of ten attributes from the LAI provided by the students represents the Critical Success Factors (CSFs) of leadership.

The attributes under scrutiny are variables amenable to mathematical manipulation like any other variables and are thus ready inputs into a quantitative model. This set forms the basis of a decision-analytic model that can be used to measure potential applicants for the onerous job of the next college president.

Measuring qualitative attributes with the objective to quantifying potential leadership effectiveness is not a well-beaten path. But it is very plausible that it will be the wave of the future if there is a good modeling tool as part of the decision and search process. The utility of a good model is best articulated by the statement below courtesy of the ACTA's Institute for Effective Governance:

"Whatever you do, remember: consensus is not the goal; selecting the most outstanding leader is. Because of our natural desire to get along, all groups tend toward consensus. But compromise decisions to achieve consensus impair the process. Today universities need to be more innovative and entrepreneurial than in the past. Institutions must respond to a dynamic economy, changing world situation, and growing calls for accountability and performance. They need bolder leaders with a wider background. Keeping your eye on the goal—selecting the most outstanding leader - is key to a successful search" (ACTA, 2003).

\subsection{Limitations}

The sample was limited to students in one institution. The sample space could be expanded to include students from other schools, departments and universities. Then there could be demographic analyses to determine if backgrounds have an influence on perceptions of leadership. 


\subsection{Future Research}

The mere fact that the attributes can be ranked implies that they are not of the same significance. Therefore the first step in using the model is to determine the weights for the attributes and clusters. A methodology like Saaty's AHP is tailor-made for a process like this (Saaty, 2008). If there are dependencies between the Critical Success Factors, as is most likely, then a modeling approach like Analytical Network Process (ANP) also by Saaty should be used to determine and calibrate the weights to further enhance the accuracy of the model.

Metrics should be developed to measure the attributes and their associated clusters in order to be better able to quantify the applicants identified in the search process.

A replication of the study with different subgroups of students possibly in different institutions may help in crystallizing the CSFs.

Students are but one facet in an n-dimensional coordinate system of a university. The faculty, staff, alumni and other stakeholders were deliberately not included in this iteration because of scope issues. It will be interesting to know if and how the chosen attributes will vary if the sample space is expanded to include these other stakeholders.

It will be useful to include all 37 attributes in a larger scalable model. If any attributes are of little significance in a particular area or culture, it will reflect during the weighting process and drop out. Such a model will be scalable and universal and will make redundant models that are customized to fit a particular environment. Table 6 shows 10 of the attributes suggested by some respondents to the question below:

Do you feel there were any desirable leadership attributes that were not listed in the survey which should have been included? If so, please identify the attributes in $\#$ s 38, 39, 40, and rate them like above.

This goes to show that the LAI can be further expanded if the need arises.

Table 6. GIMPA student addendum to LAI

\begin{tabular}{|c|c|c|}
\hline \# & Atttribute & Description \\
\hline 1 & Assertiveness & $\begin{array}{l}\text { The ability to clearly state what one expects so that there will be no } \\
\text { misunderstandings. }\end{array}$ \\
\hline 2 & Autocratic & Make final decisions sometime without accepting any views. \\
\hline 3 & Creativity & The ability to think differently, to get outside of the box that constrains solutions. \\
\hline 4 & Entrepreneur & Be able create firms for students who leave the school or graduate. \\
\hline 5 & Faith & Have faith in God \\
\hline 6 & Magnanimity & $\begin{array}{l}\text { Giving credit where it is due. A magnanimous leader ensures that credit for } \\
\text { successes is spread as widely as possible throughout the company. }\end{array}$ \\
\hline 7 & Negotiation Skills & Must have a very strong ability to negotiate. \\
\hline 8 & Patriotism & $\begin{array}{l}\text { Commitment to development of the nation, sense of corporation and collaboration } \\
\text { with the government of the day. }\end{array}$ \\
\hline 9 & Practicable & $\begin{array}{l}\text { To create an environment where students demonstrate their knowledge based on } \\
\text { studies. }\end{array}$ \\
\hline 10 & Unity of command & $\begin{array}{l}\text { The concept by which each person within an organization reports to one and only } \\
\text { one designated person. }\end{array}$ \\
\hline
\end{tabular}

\section{References}

AAUP. (1966). Statement on Government of Colleges and Universities. Retrieved from http://www.aaup.org/AAUP/pubsres/policydocs/contents/governancestatement

ACTA. (2003). Selecting a New President, What to do Before You Hire a Search Firm. Retrieved from http://www.fau.edu/botretreat/files/Category1/selecting_a_president.pdf

Bennis, W. G. (1989). On becoming a leader. Reading, Mass: Addison-Wesley Pub.

Berea College. (2012). The Search for a President. Retrieved from http://www.berea.edu/searchdocument3f.pdf 
Cowley, W. H. (1980). Presidents, professors, and trustees, the evolution of American academic government. San Francisco, CA: Jossey-Bass.

Dodds, H. W. (1962). The academic president educator or caretaker? New York, NY: McGraw-Hill Book Company.

Duderstadt, J. J. (2007). The View from the Helm Leading the American University during an Era of Change. New York: University of Michigan Press.

Frimpon, M. (2012). A Re-Structuring of the Enterprise Resource Planning Implementation Process. International Journal of Business and Social Science, 3(1).

Hogan, R., Curphy, G. J., \& Hogan, J. (1994). What We Know About Leadership: Effectiveness and Personality, American Psychologist. Retrieved from http://www.hoganassessments.com/_hoganweb/documents/What\%20We\%20Know\%20About\%20Leadersh ip.pdf

Jago, A. G. (1982). Leadership: Perspectives in theory and research. Management Science, 28(3), 315-336. http://dx.doi.org/10.1287/mnsc.28.3.315

Lazarick, L. (1999). Community colleges enter decade of CEO retirements, raising question of who will lead and how will they lead. Community College Times, 11, 8-9.

Mckenzie, K. M. (2010). Perceptions of Leadership Attributes Of South Carolina Technical College Presidents. A Dissertation Presented to the Graduate School of Clemson University. Retrieved from http://etd.lib.clemson.edu/documents/1285614498/McKenzie_clemson_0050D_10574.pdf

Moss et al. (1994). Leader attributes inventory. Berkeley, CA: National Center for Research in Vocational Education.

Moss, J. Jr., \& Liang, T. (1990). Leadership, Leadership Development and the National Center for Research in Vocational Education. Berkeley, CA: National Center for Research in Vocational Education.

Moss, Jerome et. al. (1994). Leader Effectiveness Index Manual. National Center for Research in Vocational Education, Berkeley, CA.

Robert Klitgaard. (2008). Leadership and Universities. Retrieved from http://www.cgu.edu/PDFFiles/Presidents\%20Office/Leadership_and_Universities10-30-08RK.pdf

Saaty, T. (2008). Relative Measurement and Its Generalization in Decision Making. Why Pairwise Comparisons are Central in Mathematics for the Measurement of Intangible Factors. The Analytic Hierarchy/Network Process. RACSAM, 102(2), 251-318. http://dx.doi.org/10.1007/BF03191825

Student Consultation Group. (2009). Key Qualities and Qualifications of the President of the University of Virginia: A Report by the Student Consultation Group. Retrieved from http://www.virginia.edu/presidentsearch/Student_Consultation_Group_Report.pdf

Wilkes University. (2012). Which qualities should we look for in our next president? Retrieved from http://www.wilkesbeacon.com/opinion/which-qualities-should-we-look-for-in-our-next-president-1.252865 7\#.T3QICmGqCSo 